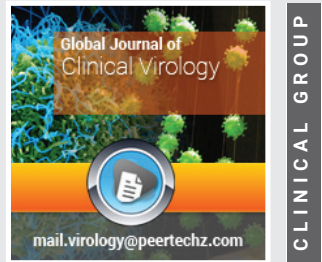

\title{
The psychological and
} gist sp.ing in Strategic Psychotherapy, Forensic Criminologist, Lawyer sp.ed SSPL, Researcher, Essayist, Italy, E-mail: giuliosr1984@hotmail.it

Keywords: COVID-19; Psychological implications; Psychopathology; Spanish flu; Asian influence; Chinese flu; Plasma therapy; Convalescent plasma https://www.peertechz.com

Check for updates

\section{Giulio Perrotta*}

Psychologist sp.ing in Strategic Psychotherapy, Forensic Criminologist, Lawyer sp.ed SSPL,

Researcher, Essayist, Italy

\section{Abstract}

Purpose: This research investigates the psychological implications arising from COVID-19-related pathological conditions and the possible relationship with previous pandemics.

Methods: The selected population sample was 765 total Italian Covid positive symptomatic and asymptomatic patients, divided into the two categories (308 symptomatic and 457 asymptomatic) and by age groups. In order to investigate these elements, an information questionnaire was specifically drawn up concerning the state of health and the period of the illness, in addition to the personal and family history and the specific indicators identified for this research.

Results: The first level concerns the psychological implication during and after the viral infection, whereby: a) symptomatic individuals with a previous psychological diagnosis (127 patients) reported medium-high values of malaise in all three areas of investigation for $51.02 \%$ (65 patients), with the high value of malaise for $48.98 \%$ (62 patients) and a consequent worsening of the previous psychopathological condition, especially for those who declared to suffer from mood, anxiety, obsessive and somatic disorders, persisting even until the sixth month after recovery; b) symptomatic individuals without a previous psychological diagnosis (330 patients) reported medium to high levels of malaise in all three surveyed areas for $72.30 \%$ (241 patients), with the highest level of malaise for $27.70 \%$ ( 89 patients) with symptoms typical of mood, anxiety, obsessive and somatic disorders, which persisted even until the sixth month after recovery; $c$ ) the asymptomatic patients with a previous psychological diagnosis (87 patients) reported medium-high levels of malaise in all three surveyed areas for $71.25 \%$ ( 62 patients), with the highest level of malaise for $28.75 \%$ ( 25 patients) and a consequent worsening of the previous psychopathological condition, especially for those who declared to suffer from mood, anxiety, obsessive and somatic disorders, lasting up to the sixth month after recovery; d) the asymptomatic patients without a previous psychological diagnosis (221 patients) reported medium-high values of malaise in all three areas of investigation for $90.55 \%$ (200 patients), with the highest value of malaise for $9.45 \%$ ( 21 patients) with symptoms typical of mood, anxiety, obsessive and somatic disorders, lasting even until the sixth month after recovery. The second level concerns the immunobiological implication, starting from the question "did your (biological) parents or grandparents contract one of the listed pandemic influences?": $80.34 \%$ (618 patients) confirmed the positive answer to the question, while the remaining 16.12\% (124 patients) answered "don't know" and 3.54\% (23 patients) answered "no".

Conclusions: Despite the limitations of this research, the data obtained make us reflect both on the hypothesis of increasing psychological support for these patients, in order to cope better with their condition, and on the immunobiological hypothesis as described above, wishing for greater attention in the future on these profiles, which are currently underestimated and overshadowed by economic and political interests on the commodification of vaccines by pharmaceutical companies. 


\section{Introduction and background}

The aim of this research work is to study the psychological implications [1-4] on symptomatic COVID-19 respiratory syndrome patients and asymptomatic positive patients in order to assess the short (within two months), medium (within four months) and long-term (within six months) effects with respect to the date of disappearance of clinical symptoms or the clinical condition implying precautionary isolation. The starting hypothesis concerns the possible immunological implication of family transmission on the immune capacities of the subject affected by COVID-19 and the consequent psychological implications, which would tend to be negatively less impactful than in a symptomatic patient or one who does not have a family history among the ancestors of the first two generations.

COVID-19, which stands for COronaVIrus Disease 19, also known as SARS-CoV-2 acute respiratory disease or coronavirus disease 2019 , is an infectious respiratory disease caused by the SARS-CoV-2 virus of the coronavirus family. The incubation period is on average between 5 and 12 days, which is why an isolation period of 14 days from possible exposure to a suspected or confirmed case has been indicated, as even during the incubation period, the person may be potentially infectious. The virus is transmitted by air, most often via respiratory droplets. The lungs are the organs most affected by COVID-19 because the virus gains access to host cells via the Angiotensin-Converting Enzyme 2 (ACE2), which is most abundant in the alveolar type II cells of the lungs. The virus uses a special surface glycoprotein called peplomerin (the spinules that give it its characteristic sunburst shape) to connect to the ACE2 receptor and enter the host cell. The density of ACE2 in each tissue correlates with the severity of the disease in that tissue and some have suggested that reducing ACE2 activity might have protective effects, while others have suggested that increasing ACE2 using angiotensin II receptor antagonist drugs might be protective but these hypotheses have yet to be tested. As the alveolar disease progresses, respiratory failure may develop and death may follow. The virus also affects the gastrointestinal organs as ACE2 is abundantly expressed in glandular cells of the gastric, duodenal and rectal epithelium, as well as in endothelial cells and enterocytes of the small intestine. The virus can cause acute myocardial injury and chronic damage to the cardiovascular system. A high incidence of thrombosis (31\%) and venous thromboembolism (25\%) has been found in ICU patients with COVID-19 infections and may be related to poor prognosis. Post-mortem histopathological examinations of lung tissue samples showed diffuse alveolar damage with exudates of fibromyxoid cells in both lungs. Cytopathic viral changes were observed in pneumocytes. The lung picture resembled that found in Acute Respiratory Distress Syndrome (ARDS). In more than half of the cases, the infection is completely asymptomatic and in about one third of the cases, flu-like symptoms are present (pauci-symptomatic form). In a minority of cases (about $5-6 \%$ of cases), the disease may occur in a moderate or severe form with risk of complications, especially respiratory (respiratory failure, ARDS). The most frequent flu-like symptoms are: fever, cough, headache, dyspnoea (shortness of breath), arthralgia and myalgia (joint and muscle pain), asthenia (tiredness) and gastrointestinal disorders such as diarrhoea; characteristic symptoms of
COVID-19 are transient anosmia (loss of smell) and aguesia (loss of taste). Disseminated intravascular coagulation and leukoerythroblastic reactions are observed in the blood. In severe cases, pneumonia, acute respiratory distress syndrome, sepsis, septic shock and a cytokine storm can occur, leading to patient death [5-7]

There is currently no definitive cure and some 156 possible specific vaccines are being tested. Therapies currently focus on the use of immunomodulatory drugs, antimalarial drugs, antiviral drugs and additional respirators. The five most frequently tested unimodal interventions were chloroquine/ hydroxychloroquine, convalescent plasma, stem cells, tocilizumab and favipiravir [8-10].

\section{Research objectives, methods, setting and partecipants}

The selected population sample is of 765 total Italian Covid positive symptomatic and asymptomatic patients, divided into the two categories (308 symptomatic and 457 asymptomatic) and by age groups $(5-10,11-15,16-20,21-25,26-30,31-35$, $36-40,41-45,46-50,51-55,56-60,61-65,66-70,71-75$, $76-80,81-85)$, with the aim of assessing the modification of adaptive styles in the three main spheres of life (emotional relationships, sentimental relationships, social relationships) and of one's own person (perception of one's own wellbeing, state of health and social condition) following the psychophysical trauma suffered [11]. The questionnaires for patients under 15 years of age were submitted directly to the parents, listening to the patients themselves in a joint session.

The distribution of the population sample is as follows:

\begin{tabular}{|c|c|c|c|c|}
\hline & Age Range & $\begin{array}{c}\text { Total } \\
\text { Interviewers }\end{array}$ & $\begin{array}{c}\% \text { In Relation to the } \\
\text { group }\end{array}$ & $\begin{array}{c}\% \text { In Relation } \\
\text { to the total }\end{array}$ \\
\hline \multirow{16}{*}{$\begin{array}{c}\text { Positive } \\
\text { Symptomatic } \\
\text { (S) }\end{array}$} & $5-10$ & 5 & $1,60 \%$ & $0,65 \%$ \\
\hline & $11-15$ & 8 & $2,56 \%$ & $1,04 \%$ \\
\hline & $16-20$ & 11 & $3,52 \%$ & $1,43 \%$ \\
\hline & $21-25$ & 13 & $4,16 \%$ & $1,69 \%$ \\
\hline & $26-30$ & 16 & $5,12 \%$ & $2,08 \%$ \\
\hline & $31-35$ & 17 & $5,44 \%$ & $2,21 \%$ \\
\hline & $36-40$ & 21 & $6,72 \%$ & $2,73 \%$ \\
\hline & $41-45$ & 22 & $7,04 \%$ & $2,86 \%$ \\
\hline & $46-50$ & 25 & $8,00 \%$ & $3,25 \%$ \\
\hline & $51-55$ & 17 & $5,44 \%$ & $2,21 \%$ \\
\hline & $56-60$ & 22 & $7,04 \%$ & $2,86 \%$ \\
\hline & $61-65$ & 22 & $7,04 \%$ & $2,86 \%$ \\
\hline & $66-70$ & 28 & $8,96 \%$ & $3,64 \%$ \\
\hline & $71-75$ & 32 & $10,24 \%$ & $4,16 \%$ \\
\hline & $76-80$ & 36 & $11,52 \%$ & $4,68 \%$ \\
\hline & $81-85$ & 13 & $4,16 \%$ & $1,69 \%$ \\
\hline \multirow{16}{*}{$\begin{array}{c}\text { Positive } \\
\text { Asymptomatic } \\
\text { (A) }\end{array}$} & $5-10$ & $7 v$ & $1,54 \%$ & $0,91 \%$ \\
\hline & $11-15$ & 11 & $2,42 \%$ & $1,43 \%$ \\
\hline & $16-20$ & 14 & $3,08 \%$ & $1,82 \%$ \\
\hline & $21-25$ & 29 & $6,38 \%$ & $3,77 \%$ \\
\hline & $26-30$ & 19 & $4,18 \%$ & $2,47 \%$ \\
\hline & $31-35$ & 37 & $8,14 \%$ & $4,81 \%$ \\
\hline & $36-40$ & 35 & $7,70 \%$ & $4,55 \%$ \\
\hline & $41-45$ & 44 & $9,68 \%$ & $5,72 \%$ \\
\hline & $46-50$ & 21 & $4,62 \%$ & $2,73 \%$ \\
\hline & $51-55$ & 21 & $4,62 \%$ & $2,73 \%$ \\
\hline & $56-60$ & 32 & $7,04 \%$ & $4,16 \%$ \\
\hline & $61-65$ & 37 & $8,14 \%$ & $4,81 \%$ \\
\hline & $66-70$ & 41 & $9,02 \%$ & $5,33 \%$ \\
\hline & $71-75$ & 47 & $10,34 \%$ & $6,11 \%$ \\
\hline & $76-80$ & 51 & $11,22 \%$ & $6,63 \%$ \\
\hline & $81-85$ & 11 & $2,42 \%$ & $1,43 \%$ \\
\hline
\end{tabular}


In order to investigate these elements, an information questionnaire was specifically prepared concerning the state of health and the period of the illness, in addition to the personal and family history and the specific indicators identified for this research. In the period of a prolonged pandemic, the clinical interview and questionnaires were administered through the use of telematic digital communication platforms (whatsapp video / skype).

The research started in March 2020 and was completed in December 2020

\section{Results, limits and possible conflicts of in- terest}

The selected sample of the population was subjected to the administration of the information questionnaire, at two months intervals (2, 4 and 6 months) after the disappearance of clinical symptoms or asymptomatic positive status. In appendice il questionario dettagliato.

Everyone was guaranteed anonymity.

The results of the selected population sample gave two different levels of value:

1) First level: The psychological implications. The originally selected population sample (765 patients, of whom 308 were symptomatic and 457 asymptomatic) can be divided into four categories:

a) Symptomatic with previous psychological diagnosis (127 patients): The specific population sample reported medium to high levels of malaise in all three areas of investigation for $51.02 \%$ (65 patients), with high levels of malaise for $48.98 \%$ (62 patients) and a consequent worsening of the previous psychopathological condition, especially for those who declared suffering from mood, anxiety, obsessive and somatic disorders [12-29], which persisted even up to the sixth month after recovery. Those who declared personality disorders [30,31] remained substantially unchanged, with a resumption of the previously stable condition from the second month of recovery.

b) Symptomatic patients without previous psychological diagnosis (330 patients): The specific population sample reported medium to high levels of malaise in all three areas of investigation for $72.30 \%$ (241 patients), with the highest level of malaise for $27.70 \%$ ( 89 patients) with the marked presence of symptoms typical of mood, anxiety, obsessive and somatic disorders [12-29], which persisted even up to the sixth month after recovery.

c) Asymptomatic patients with a previous psychological diagnosis (87 patients): The sample of the specific population reported medium-high values of malaise in all three areas of investigation for $71.25 \%$ (62 patients), with the high value of malaise for $28.75 \%$ ( 25 patients) and a consequent worsening of the previous psychopathological condition, especially for those who declared to suffer from mood, anxiety, obsessive and somatic disorders [12-29], lasting even until the sixth month after recovery. Those who declared personality disorders
$[30,31]$ remained substantially unchanged, with a resumption of the previously stable condition from the second month of recovery.

d) Asymptomatic patients without previous psychological diagnosis (221 patients): The specific population sample reported medium to high levels of malaise in all three areas of investigation for $90.55 \%$ (200 patients), with the highest level of malaise for $9.45 \%$ ( 21 patients) with the marked presence of symptoms typical of mood, anxiety, obsessive and somatic disorders [12-29], which persisted even up to the sixth month after recovery.

2) Second level: Immunobiological implications: Among the questions in the questionnaire is a question aimed at knowledge of a specific fact: "Did your (biological) parents or grandparents contract one of the listed influences?". The three most important pandemics of the twentieth century (Spanish flu, Asian flu and Chinese flu) were deliberately included in the answers, as data needed to be obtained in relation to the starting hypothesis: "Is it true that if ancestors up to the second generation have contracted one of the three listed pandemic influences, descendants have a greater chance of being asymptomatically positive?". The data from the questionnaires clearly confirm this hypothesis: $80.34 \%$ (618 patients) confirmed the positive response to the question, while the remaining $16.12 \%$ (124 patients) answered 'don't know' and 3.54\% (23 patients) answered 'no'. In this regard, the data is very interesting because of its high correspondence. We know that three influenza pandemics occurred in the twentieth century: in 1918, 1957 and 1968, which are commonly identified according to their presumed area of origin: Spanish, Asian and Hong Kong; we also know that they were caused by three different antigenic subtypes of the influenza A virus, respectively $\mathrm{H} 1 \mathrm{~N} 1, \mathrm{H} 2 \mathrm{~N} 2$, and $\mathrm{H} 3 \mathrm{~N} 2$, and that they have nothing to do genetically with COVID-19 (the former being an avian influenza virus) although they have diffusion tendencies in common. The three possible hypotheses that could explain this finding could be the following:

a) Immunological hypothesis: Despite the lack of immunobiological correlation between the previous pandemics and that of COVID-19, the immunity of the ascendants after the infections may have been genetically transmitted, thus strengthening the immune defenses against the viral agent able (in the clinic) to promote uncontrolled coagulation capable of causing damage first to the vascular system and then to the respiratory and finally cardiac. From the data obtained it would seem that having infected and healed ancestors would guarantee the patient a certain immune coverage able to avoid the onset of the more aggressive and symptomatic form, in favor of the asymptomatic and milder one. Therefore, the plasma of these cured patients could be an excellent clinical tool to be administered in the early stages of infection, if not even in a preventive manner as is done in the hypothesis of administering vaccine therapy, obviously with completely different mechanisms. If this hypothesis were to be confirmed, it would open the door to the most suggestive therapeutic hypothesis: taking plasma from cured and asymptomatic patients in order to 'vaccinate' the entire population, with a 
much lower risk of rejection/complications than the vaccines tested in recent months, which are tested on small and often non-representative samples of the population, and for much shorter periods of time than the normal procedure envisaged and approved [32-39].

b) Statistical hypothesis: The population sample selected, not being sufficiently representative of the current number of official infections, would distort the value obtained, which would be correctly re-proportioned if the sample were quantitatively higher. If this hypothesis were to be confirmed, it would in any case open up interesting scenarios with regard to immunobiological profiles and the "vaccination" by means of plasma of cured and/or asymptomatic patients (as opposed to experimental vaccines).

c) Probabilistic hypothesis: The immunobiological comparison is based on worldwide pandemic events; therefore, the final number of infections in the pandemics examined may have distorted the data obtained since it is difficult not to find ancestors who have been infected by one of those three pandemics. If this hypothesis were to be confirmed, it would in any case open up useful scenarios with regard to immunobiological profiles and the 'vaccination' of cured and/ or asymptomatic patients by means of plasma (as opposed to experimental vaccines).

The limitations of this research are mainly related to the quantity of the sample selected, which is not sufficiently representative; however, taking into account the percentages obtained, the results of the research can be considered reliable and worthy of further study with a larger sample.

As this research is not financed by any private body or subject, it does not present any conflict of interest.

\section{Conclusion}

The present research work was carried out to study the psychological implications [1-4] of COVID-19 symptomatic and asymptomatic positive patients with respiratory syndrome, in order to assess the short (within two months), medium (within four months) and long term (within six months) effects with respect to the date of disappearance of clinical symptoms or the clinical condition implying precautionary isolation.

The selected population sample is 765 total Italian Covid positive symptomatic and asymptomatic patients, divided into the two categories (308 symptomatic and 457 asymptomatic) and by age groups, in order to evaluate the modification of the adaptive styles in the three main spheres of life (emotional relationships, sentimental relationships, social relationships) and of one's own person (perception of one's own well-being, of one's own state of health and of one's own social condition), in three consequential time periods (2, 4 and 6 months after recovery).

The results of the selected population sample yielded two different levels of value: psychological and immunobiological implication. In spite of the limitations of this research (which are mainly related to the quantity of the selected sample that is not sufficiently representative), the data obtained make us reflect both on the hypothesis of increasing the psychological support to these patients, in order to better cope with their condition, and on the immunobiological hypothesis as described above, hoping for more attention in the future on these profiles that are currently underestimated and put in the background due to economic and political interests on the commodification of vaccines by pharmaceutical companies.

(Appendix)

\section{References}

1. Perrotta G (2019) Psicologia generale, Luxco Ed. 1st ed.

2. Perrotta G (2019) Psicologia dinamica, Luxco Ed., 1st ed.

3. Perrotta G (2019) Psicologia clinica, Luxco Ed., 1st ed.

4. APA (2013) DSM-V. Washington

5. Moroni M (2020) Manuale di malattie infettive, Edra - Masson

6. Zhou MY, Xie XL, Peng YG, Wu MJ, Deng XZ, et al. (2020) From SARS to COVID-19: What we have learned about children infected with COVID-19. Int J Infect Dis 96: 710-714. Link: https://bit.ly/3iwnXNj

7. Esakandari H, Nabi-Afjadi M, Fakkari-Afjadi J, Farahmandian N, Miresmaeil SM, et al. (2020) A comprehensive review of COVID-19 characteristics. Biol Proced 22: 19. Link: https://bit.ly/3qwCXXY

8. Shanmugaraj B, Siriwattananon K, Wangkanont K, Phoolcharoen W, et al. (2020) Perspectives on monoclonal antibody therapy as potential therapeutic intervention for Coronavirus disease-19 (COVID-19). Asian Pac J Allergy Immunol 38: 10-18. Link: https://bit.ly/3iv0BI1

9. Karlsen $\mathrm{APH}$ (2020) A systematic review of trial registry entries for randomized clinical trials investigating COVID-19 medical prevention and treatment. PLoS ONE 15. link: https://bit.ly/3qChL9k

10. Harapan H, Itoh N, Yufika A, Winardi W, Keam S, et al. (2020) Coronavirus disease 2019 (COVID-19): A literature review. J Infect Public Health 13: 667673. Link: https://bit.ly/39UGwGW

11. Perrotta G (2020) Psychological trauma: definition, clinical contexts, neural correlations and therapeutic approaches Recent Discoveries. Curr Res Psychiatry Brain Disord CRPBD-100006. Link: https://bit.ly/394qdlu

12. Perrotta G (2019) Anxiety disorders: definitions, contexts, neural correlates and strategic therapy. J Neur Neurosci 6: 046. Link: https://bit.ly/35YT7rD

13. Perrotta G (2019) Neural correlates in eating disorders: Definition, contexts and clinical strategies. J Pub Health Catalog 2: 137-148. Link: https://bit.ly/35XI3Lg

14. Perrotta G (2019) Post-traumatic stress disorder: Definition, contexts, neural correlations and cognitive-behavioral therapy. J Pub Health Catalog 2: 40-47. Link: https://bit.ly/2M9vpSm

15. Perrotta G (2019) Sleep-wake disorders: Definition, contexts and neural correlations. J Neurol Psychol 7: 09. Link: https://bit.ly/3p5Zvom

16. Perrotta G (2019) Depressive disorders: Definitions, contexts, differential diagnosis, neural correlates and clinical strategies. Arch Depress Anxiety 5 : 009-033. Link: https://bit.ly/3p88ky3

17. Perrotta G (2019) Tic disorder: definition, clinical contexts, differential diagnosis, neural correlates and therapeutic approaches. J Neurosci Rehab 2019: 1-6. Link: https://bit.ly/2Nq9h71 
18. Perrotta G (2019) Panic disorder: definitions, contexts, neural correlates and clinical strategies. Curr Tr Clin Med Sci 1: 2019.Link: https://bit.ly/2M4BPCh

19. Perrotta G (2019) Obsessive-Compulsive Disorder: definition, contexts, neura correlates and clinical strategies. Cientific Journal of Neurology 1: 08-16. Link: Link: https://bit.ly/2XZdgcG

20. Perrotta G (2019) Behavioral addiction disorder: definition, classifications clinical contexts, neural correlates and clinical strategies. J Addi Adol Beh 2. Link: https://bit.ly/2MaJA9X

21. Perrotta G (2019) Paraphilic disorder: definition, contexts and clinical strategies. Journal of Addiction Neuro Research 1: 4. Link: https://bit.ly/390vgK6

22. Perrotta G (2019) Internet gaming disorder in young people and adolescent a narrative review. Journal of Addiction Research and Adolescent Behavior. J Addi Adol Beh 2(2), doi: 10.31579-007/ 2688-7517/013.

23. Perrotta G (2019) Bipolar disorder: definition, differential diagnosis, clinical contexts and therapeutic approaches. J Neuroscience and Neurological Surgery 5. Link: https://bit.ly/2XXcpcj

24. Perrotta G (2020) Suicidal risk: definition, contexts, differential diagnosis, neural correlates and clinical strategies. J Neuroscience Neurological Surgery 6: 114. Link: https://bit.ly/39Q00S6

25. Perrotta G (2020) Pathological gambling in adolescents and adults: definition clinical contexts, differential diagnosis, neural correlates and therapeutic approaches. ES J Neurol 1: 1004. Link: https://bit.ly/3iyiBR

26. Perrotta G (2020) Dysfunctional sexual behaviors: definition, clinical contexts, neurobiological profiles and treatments. Int J Sex Reprod Health Care 3: 061 069. Link: https://bit.ly/3nZbdjf

27. Perrotta G (2020) Perrotta Integrative Clinical Interview. LK ed., I ed., pag 270 formato A5.

28. Perrotta G (2020) The structural and functional concepts of personality: The new Integrative Psychodynamic Model (IPM), the new Psychodiagnostic Investigation Model (PIM) and the two clinical interviews for the analysis of personality disorders (Perrotta Integrative Clinical Interview or $\mathrm{PICl}$ ) for adults and teenagers (1TA version) and children (1C version). Psychiatry Peertechz E-book. Link: https://bit.ly/2LRrmdF
29. Perrotta G (2020) First revision of the Psychodiagnostic Investigation Mode (PIM-1R) and elaboration proposal of a clinical interview for the analysis of personality disorders (Perrotta Integrative Clinical Interview or $\mathrm{PICl}-1$ ) for adults, teenagers and children. Link: https://bit.ly/392ZFYg

30. Perrotta G (2020) Borderline Personality Disorder: definition, differential diagnosis, clinical contexts and therapeutic approaches. Ann Psychiatry Treatm 4: 043-056. Link: https://bit.ly/394iJ8m

31. Perrotta G (2020) Narcissism and psychopathological profiles: definitions, clinical contexts, neurobiological aspects and clinical treatments. J Clin Cases Rep 4: 12-25. Link: https://bit.ly/2M4uUZP

32. Bloch EM, Shoham S, Casadevall A, Sachais BS, Shaz B, et al. (2020) Deployment of convalescent plasma for the prevention and treatment of COVID-19. J Clin Invest 130: 2757-2765. Link: https://bit.ly/3sIHq22

33. Brown BL, McCullough J (2020) Treatment for emerging viruses: Convalescent plasma and COVID-19. Transfus Apher Sci 59: 102790. Link: https://bit.ly/39PLGnR

34. Rojas $M$, Rodríguez $Y$, Monsalve DM, Acosta-Ampudia $Y$, Camacho $B$, et al. (2020) Convalescent plasma in Covid-19: Possible mechanisms of action. Autoimmun Rev 19: 102554. Link: https://bit.ly/393iSJ7

35. Shen C, Wang Z, Zhao F, Yang Y, Li J, et al. (2020) Treatment of 5 Critically III Patients With COVID-19 With Convalescent Plasma. JAMA 323: 1582-1589. Link: https://bit.ly/3obY9rb

36. Tiberghien $\mathrm{P}$, Lamballerie $\mathrm{X}$, Morel $\mathrm{P}$, Gallian $\mathrm{P}$, Lacombe $\mathrm{K}$, et al (2020) Collecting and evaluating convalescent plasma for COVID-19 treatment: why and how? Vox Sang 115: 488-494. Link: https://bit.ly/3bXClg9

37. Yiğenoğlu TN, Hacıbekiroğlu T, Berber I, Sinan Dal M, Baștürk A, et al. (2020) Convalescent plasma therapy in patients with COVID-19. J Clin Apher 35: 367373. Link: https://bit.ly/3p3rBAB

38. Malani AN, Sherbeck JP, Malani PN (2020) Convalescent Plasma and COVID-19. JAMA 324: 524. Link: https://bit.ly/2M7uEtd

39. Barone P, DeSimone RA (2020) Convalescent plasma to treat coronavirus disease 2019 (COVID-19): considerations for clinical trial design. Transfusion 60:1123-1127. Link: https://bit.ly/2MdXasT

\section{Discover a bigger Impact and Visibility of your article publication with} Peertechz Publications

\section{Highlights}

* Signatory publisher of ORCID

* Signatory Publisher of DORA (San Francisco Declaration on Research Assessment)

* Articles archived in worlds' renowned service providers such as Portico, CNKI, AGRIS, TDNet, Base (Bielefeld University Library), CrossRef, Scilit, J-Gate etc.

* Journals indexed in ICMJE, SHERPA/ROMEO, Google Scholar etc.

* OAl-PMH (Open Archives Initiative Protocol for Metadata Harvesting)

* Dedicated Editorial Board for every journa

* Accurate and rapid peer-review process

* Increased citations of published articles through promotions

* Reduced timeline for article publication

Submit your articles and experience a new surge in publication services

(https://www.peertechz.com/submission).

Peertechz journals wishes everlasting success in your every endeavours.

Copyright: (c) 2021 Perrotta G. This is an open-access article distributed under the terms of the Creative Commons Attribution License, which permits unrestricted use, distribution, and reproduction in any medium, provided the original author and source are credited. 